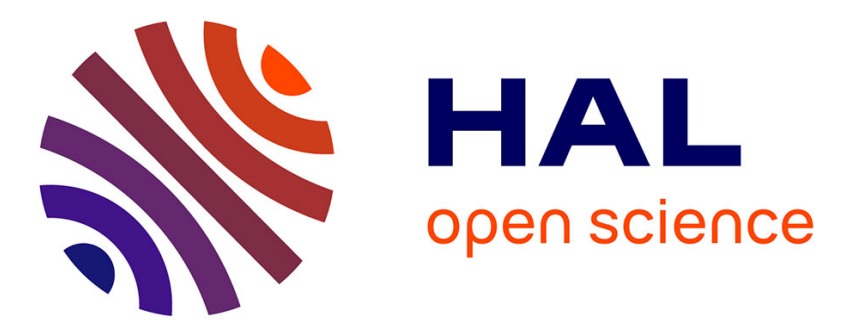

\title{
Easy clip to treat anal fistula tracts: a word of caution
}

M Gautier, P. Godeberge, R. Ganansia, G. Bozio, B. Godart, M. A. Bigard, M. Barthet, L. Siproudhis

\section{To cite this version:}

M Gautier, P. Godeberge, R. Ganansia, G. Bozio, B. Godart, et al.. Easy clip to treat anal fistula tracts: a word of caution. International Journal of Colorectal Disease, 2015, 30 (5), pp.621-624. 10.1007/s00384-015-2146-5 . hal-01154233

\section{HAL Id: hal-01154233 \\ https://hal-univ-rennes1.archives-ouvertes.fr/hal-01154233}

Submitted on 14 Sep 2015

HAL is a multi-disciplinary open access archive for the deposit and dissemination of scientific research documents, whether they are published or not. The documents may come from teaching and research institutions in France or abroad, or from public or private research centers.
L'archive ouverte pluridisciplinaire HAL, est destinée au dépôt et à la diffusion de documents scientifiques de niveau recherche, publiés ou non, émanant des établissements d'enseignement et de recherche français ou étrangers, des laboratoires publics ou privés. 


\title{
Easy clip to treat anal fistula tracts: a word of caution
}

\author{
M.Gautier, P.Godeberge, R.Ganansia, G.Bozio, B.Godart, M.A Bigard, M.Barthet, L.Siproudhis \\ Paris, Lyon, Tours, Nancy \& Marseille.
}

\begin{abstract}
Background and aims: Closing the internal opening by a clip ovesco has been recently proposed for healing the fistula tract, but, to date, data on benefit are poorly analysed. The aim was to report a preliminary multicentre experience.

Materials and methods: Rectrospective study undertaken in 6 different French centres: surgical procedure, immediate complications and follow up have been collected.

Results: 19 clips were inserted in 17 patients (M / F: 4/13. Median age: 42 years [29-54]) who had an anal fistula: 12 (71\%) high fistulas (including 4 recto-vaginal fistulas), 5 (29\%) lower fistulas (with 3 recto-vaginal fistulas), $6(35 \%)$ Crohn's fistulas. Out of 17 patients, 15 had a seton drainage beforehand. The procedure was easy in $8(47 \%)$ patients and the median operative time was 27.5 minutes [20-36.5]. Postoperative period was painful for $11(65 \%)$ patients. A clip migration was noted in 11 patients $(65 \%)$ after a median follow up of 10 days [5.5-49.8]. Eleven patients $(65 \%)$ who failed, had reoperation including 10 new drainages within the first month [0.5-5]. After a mean followup of 4 months [2-7], closing the tract was observed in 2 patients (12\%) following the first insertion of the clip and in another one after a second insertion.

Conclusion: Treatment of anal fistula by placing a clip on the internal opening is disappointing and deleterious for some patients. A better assessment before dissemination is recommended.
\end{abstract}

\section{Conflict of interest statement None}

Key words Anorectal $\cdot$ Rectovaginal fistula $\cdot$ Clip Ovesco $\cdot$ Feasibility $\cdot$ Safety

Word Counts 2028 words

\section{Introduction}

The American Society of Colon and Rectal Surgeons recently revised its practice parameters for the management of fistula-in-ano. The main treatment goal remains to obliterate the internal fistulous opening and any associated reepithelialised tracks with minimal sphincter division. Sphincter sparing methods are numerous but data are too preliminary to make a formal strategy (usually weak recommendations) [1]. For the ACPGBI position statement, the aims of surgery "are to cure the fistula while at the same time preserving anal sphincter function" but it is not possible to be prescriptive on the management of each type of fistula [2]. Beside rectal advancement flap, new strategies have been developed such as fibrin glue and plug. Despite early enthusiastic series, controlled trials and longer follow-up have pointed out high failure and recurrence rates [3] (Getaid Gy). Thus, new techniques are under survey. Clipping the internal opening is a challenging strategy since the technique is easily reproducible and the early results promising [4]. The objective of this pilot multicenter study was to assess the feasibility and safety of this new sphincter sparing procedure to treat anal fistula.

\section{Patients and Methods}

All patients with transsphincteric or suprasphincteric anal fistulae who underwent a surgical procedure using the Clip OVESCO were retrospectively recorded. Only transsphincteric single-tract fistulas without any evidence of severe inflammation activity or perineal sepsis were analyzed. Between April 2010 and October 2013, patients were eligible if they had a fistula according to the classification of Parks or a recto-vaginal fistula. It could be fistula of Crohn's disease. In some patient, a seton has been 
placed into the fistula tract at least six weeks before fistula closure. Patients with recto-seminal, colorectal, recto-cutaneous, ileo-colic and ileo-transverse fistula have been excluded. The dataset of first french patients who received a clip OVESCO were retrospectively collected. Six surgeons took part in the study. The recorded items were: age and gender of the patient, height and fistula tract, Crohn's disease context, seton drainage, length of suppuration, difficulty of technique, duration of procedure, post-operative pains, duration of immobilisation, residual complaints, emerging of a secondary abscess, need for a new wave of drainage, persistent fistula tract, removal or migration of the clip.

Surgery was realized according to a standardized operative pathway described elsewhere by Prosst et al [4]. The same video sequence (personal Prosst procedure) was used for the teaching tutorial. Briefly, the patient was positioned in supine position under general or spinal anesthesia. An excision of anoderm around the internal opening of the fistula, the removal of the loosing seton and a debridement of the fistula tract were performed before two U shaped sutures were placed internally, centred around the internal opening. The clip was released from the applicator cap and placed closed to the internal opening in parallel to the axis of the anal canal. The stitches were removed and the external opening was cored out in order to improve the drainage of the fistula tract. Major steps of surgical technique are outlined in Figure 1. Laxatives and analgesic tablets were provided in the postoperative period.

Statistical analysis

Quantitative variables were expressed as median and percentile (interquartile range [IQR], 25\% and 75\%). Categorical variables were presented as counts and percent.

Ethical considerations

The study was approved by the CHU Ethics Committee of Rennes $\left(\mathrm{N}^{\circ} 13 / 2107^{\mathrm{TH}}\right.$ June 2013$)$ and the Commission Nationale Informatique et Liberté (CNIL no.1412467).

\section{Results}

The individual results are summarized in the table 1 according with their own past history, the surgical procedure and the follow-up. Nineteen clips have been placed in 17 patients (M/F:4/13; median age:42 [29-54] years). The fistula tract was drained (loose setons in 15) for a long period of time before the procedure (median period of drainage: 26 months [14-60]). Twelve patients (71\%) had a high or complex fistula tract (4 recto-vaginal fistulas, 1 suprasphincteric fistula, 6 transsphincteric fistulas and 1 urethra-rectal fistula) and 5 (29\%) patients had a low fistula (with 3 low recto-vaginal fistulas). Six (35\%) patients had a Crohn's disease, and $2(12 \%)$ patients reported a past history of pelvic radiotherapy. The median follow-up was 4 months [2-7] after the first insertion of the clip.

The surgical procedure (mainly ambulatory) was easy in $8(47 \%)$ patients with a median duration of 27.5 [20-36.5] minutes. Postoperative period was painful for $11(65 \%)$ patients but the median resting period was 4 days [2-10.5]. After surgery, 13 (76\%) patients complained of persistent discharge and 2 (12\%) patients reported residual pain. The fistula tract was unhealed in 15 patients: a new abscess or collection was observed in $9(53 \%)$ patients.

A clip migration was reported in $11(65 \%)$ patients ( 9 high fistulas, 1 recto-vaginal fistula and 1 transsphincteric fistula) after a median follow-up of 10 days [5.5-49.8]. A new procedure was mandatory in 11 patients (65\%), mainly for a new drainage (10 patients) within the first month [0.5-5] of follow-up. Primary healing of the tract was observed in 2 patients (12\%) after the first insertion of the clip and in another one after a second insertion.

\section{Discussion}


This consecutive series of cases did not mainly benefit of the clip procedure since only $18 \%$ closed the fistula tract after a short follow-up. The most postoperative events were clip migrations or removals, secondary abscesses and post-operative pains.

The main limitations of our study are the initial experience and the retrospective collect of the data. These results however contrast with those published by L. Prosst in 2013 where he reported a high success rate in 9 out of the 10 patients. Nevertheless, he described five dropping clips, not having prevented the closure of the route except for one patient who lost the clip too early [4]. Moreover, we observed several more severe sepsis after the procedure since the internal opening has been enlarged by the migration of the clip into the internal space, thus inducing a larger internal sphincter defect.

This discrepancy in healing rates may be multifactorial but it highlights both the complex nature of the fistula and an easy but non-reproducible procedure. The manipulation of operative bed and the scarring (especially from repeated surgeries) would have rendered the surrounding tissue ischemic. The devascularisation of native tissues induced by the clip grasping may also induce sphincter lesions. By contrast to the gut, the anal canal is a high-pressure zone, which is submitted to frequent mechanical variations: this will explain the clip migration and pain. Differences in surgical techniques cannot be advocated since we scrupulously applied the simple and original procedure described elsewhere.

Due to these limitations, this new procedure needs further technical adaptations and a better assessment before dissemination. Individual experiences have to be discouraged.

\section{References}

1. Steele SR, Kumar R, Feingold DL, Rafferty JL, Buie WD. Practice parameters for the management of perianal abscess and fistula-in-ano. Dis Colon Rectum. 2011;54:1465-74.

2. Williams JG, Farrands PA, Williams AB, Taylor BA, Lunniss PJ, et al. The treatment of anal fistula: ACPGBI position statement. Colorectal Dis. 2007;9 Suppl 4:18-50.

3. Grimaud JC, Munoz-Bongrand N, Siproudhis L, Abramowitz L, Sénéjoux A, et al. Fibrin glue is effective healing perianal fistulas in patients with Crohn's disease. Gastroenterology. 2010;138:227581

4. Prosst RL, Ehni W, Joos AK. The OTSC® Proctology clip system for anal fistula closure: first prospective clinical data. Minim Invasive Ther Allied Technol. 2013;22:255-9.

Figure 1. Surgical technique: (A) clip applicator, (B) debridement of the fistula tract with the fistula brush, (C) passage of the sutures, centering the internal opening, into the clip applicator, and releasing the clip (D) final situation with the clip on the internal fistula opening. 


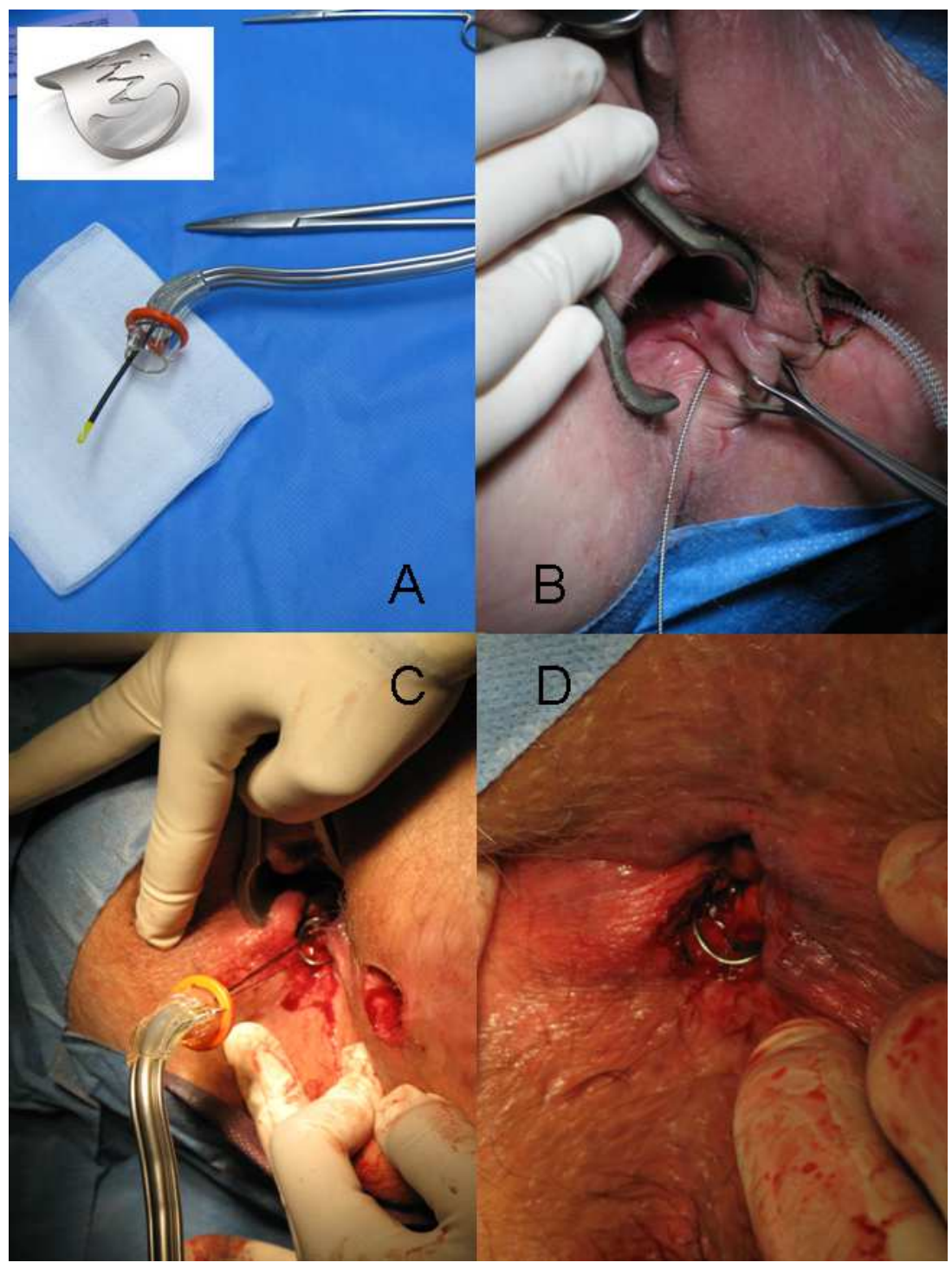




\section{Past history}

$\operatorname{sex}$

median age (y.)

Crohn's disease

fistula tract

rectovaginal fistula

inserted seton

median fistula duration (m.)

\section{Surgical procedure}

hability to perform the procedure median procedure duration (min)

post operative pain

immobilisation (d.)

median follow up (m.)

\section{Follow-up}

residual complains

spontaneous migration of the clip median duration before migration (d.)

persistance of the fistula tract

new abscess

new drainage

median duration before new surgery (m.)

removal of the clip

Abbreviations d.:days. m.: month

\begin{tabular}{|c|c|c|c|c|c|c|c|c|c|c|c|c|c|c|c|c|}
\hline $\mathrm{F}$ & $\mathrm{M}$ & $\mathrm{F}$ & $\mathrm{F}$ & $\mathrm{F}$ & $\mathrm{M}$ & $\mathrm{M}$ & $\mathrm{M}$ & $\mathrm{F}$ & $\mathrm{F}$ & $\mathrm{F}$ & $\mathrm{F}$ & $\mathrm{F}$ & $\mathrm{F}$ & $\mathrm{F}$ & $\mathrm{F}$ & $\mathrm{F}$ \\
\hline 46 & 49 & 24 & 61 & 27 & 54 & 62 & 86 & 49 & 42 & 42 & 29 & 55 & 31 & 40 & 29 & 28 \\
\hline yes & no & yes & no & yes & no & no & no & yes & no & no & no & no & no & no & yes & \\
\hline high & high & high & low & low & high & high & high & high & low & low & high & high & high & high & high & \\
\hline yes & no & no & yes & no & no & no & no & yes & yes & yes & yes & yes & no & no & no & \\
\hline yes & yes & yes & no & yes & yes & yes & yes & yes & yes & yes & no & yes & yes & yes & yes & \\
\hline 10 & 26 & 51 & 48 & 68 & 60 & 48 & 22 & 60 & 70 & 8 & 14 & 3 & 1 & 18 & 17 & \\
\hline
\end{tabular}

easy easy mod. mod. easy mod. mod. diff. diff. mod. mod. mod. easy easy easy easy easy

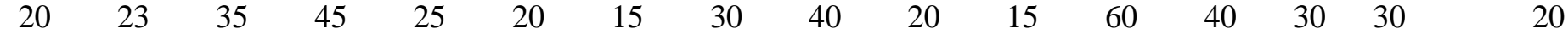

mod. high high no mod. low high low mod. mod. high no mod. no low high high

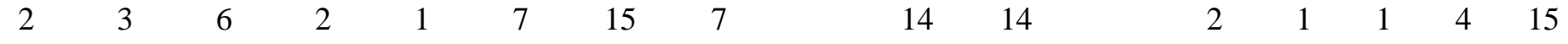

$\begin{array}{lllllllllllllllll}5 & 12 & 8 & 2 & 3 & 13 & 12 & 1 & 6 & 2 & 7 & 0 & 1 & 2 & 4 & 6 & 3\end{array}$

disch. disch. disch. disch. disch. disch. disch. disch. disch. disch. disch. disch. disch. pain pain

\begin{tabular}{|c|c|c|c|c|c|c|c|c|c|c|c|c|c|c|c|c|}
\hline yes & yes & yes & non & yes & yes & yes & yes & yes & yes & no & no & no & yes & no & yes & no \\
\hline 33 & 100 & 120 & & 10 & & 160 & & 10 & 4 & & & & & & 4 & \\
\hline yes & yes & yes & yes & yes & yes & yes & yes & yes & yes & yes & yes & yes & no & no & yes & yes \\
\hline yes & yes & yes & yes & yes & no & yes & no & no & no & yes & no & yes & no & no & yes & no \\
\hline yes & yes & yes & no & yes & non & yes & yes & no & yes & yes & no & yes & no & no & yes & no \\
\hline 1 & 6 & 4 & & 0 & 11 & 0 & 1 & & & 7 & & 0 & & 4 & 1 & \\
\hline yes & yes & yes & no & yes & yes & no & no & no & no & no & no & oui & no & yes & no & no \\
\hline
\end{tabular}

Table 1: main characteristics of the population study according to the past history, surgical procedure and follow-up 